General Paper

\title{
A New Aqueous Developable Positive Tone Photodefinable Polyimide for a Stress Buffer Coat of Semiconductor; HD-8000
}

\author{
Masataka Nunomura and Masayuki Ohe \\ Yamazaki Research \& Development Center, Hitachi Chemical DuPont Micro Systems Co.Ltd., \\ 13-1, Higashi-cho 4-chome, Hitachi-shi, Ibaraki 317-8555, Japan
}

\begin{abstract}
A new aqueous developable positive tone photodefinable polyimide was prepared from poly(hydroxy amic acid) and naphthoquinonediazide for semiconductor stress buffer coat, which exhibits excellent photolithographic properties in high resolution, wide focus latitude and good stability for process holding time, with equivalent film properties to conventional non-photodefinable polyimide. Through dry etching evaluation of the $\mathrm{SiN}$ passivation layer, it was confirmed that the cured polyimide pattern works as an etching mask.
\end{abstract}

Keywords: polyimide, aqueous developable, positive tone, photodefinable

\section{Introduction}

In semiconductor manufacture, polyimides are applied on a wide range of devices as a passivation film (a stress buffer coat), because of their excellent thermal and mechanical properties [1]. Recently, the use of photodefinable polyimides (PDPIs), especially aqueous developable positive tone PDPIs, has been increasing. PDPIs can simplify pattern-defining processes in comparison with non-PDPIs. In addition, aqueous developable positive tone PDPIs are preferable to solvent developable negative tone PDPIs in virtue of the following benefits.

- Compatibility of process machines and reticles for photoresist.

- Scum less after development,

- Higher resolution,

- Less environmental concem in waste disposal,

To realize an aqueous developable positive tone PDPI, various systems have been proposed [2]-[12]. From the viewpoint of photodefinable mechanisms, these systems can be roughly classified into two groups: naphthoquinonediazide (NQD) systems and chemical amplification systems. We considered that the NQD system is more beneficial for an aqueous positive tone PDPI, because the NQD system needs no post exposure bake (PEB) and shows wider process margin.
For the NQD system, poly(amic acid)s (PAAs) [2][3], poly(hydroxy amic acid ester)s (PAEs) [4][5] and soluble poly(hydroxy imide)s (SPIs) [6][7] have been reported. A precursor of polybenzoxazole (PBO), which is not a polyimide but shows equivalent thermal and mechanical properties, has also been reported [6]. These were published independently, so it is difficult to ascertain which will be the most feasible for the purpose.
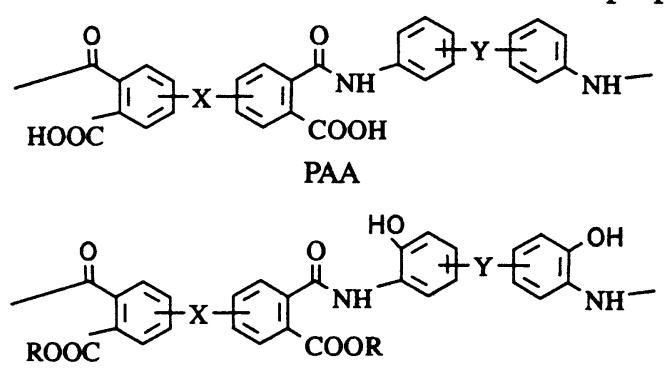

PAE
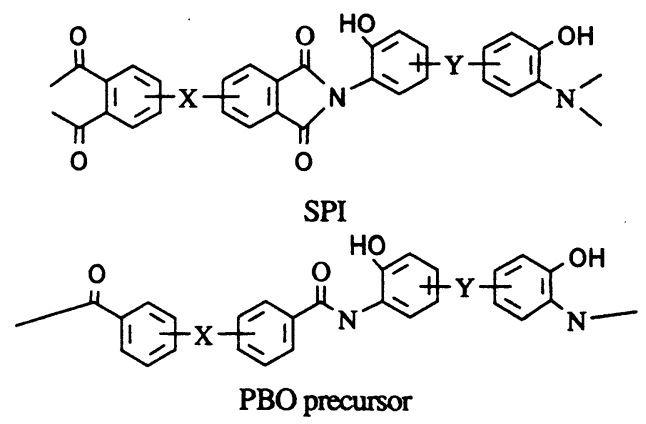

Figure 1 Polymer structures 
We compared these polymers in their photolithographic, thermal and mechanical properties [13]. To standardize the comparison, the same moieties indicated by $X$ and $Y$ in Figure 1 were chosen. The PAA showed a low photolithographic contrast due to the less dissolution inhibition at the unexposed area; the contrast is defined as the dissolution rate ratio of the exposed area to the unexposed area. The contrast for the SPI was not high because of the low dissolution promotion at the exposed area. The PAE and the PBO precursor showed high contrasts and were expected to realize good photolithographic properties.

The cured film from the PAE formulation demonstrated no delamination by the cross-cut method after 500 hours of PCT (pressure cracker test: $121^{\circ} \mathrm{C}, 2$ $\mathrm{atm}$ ), while the PBO film was peeled off only after 10 hours of PCT.

Based on the above results, a new aqueous positive tone PDPI consisting of PAE, HD-8000, was developed with the optimization of the NQD compound and the other additives for further improvement of photolithographic properties. In this paper, the photolithographic and film properties of HD-8000 are. described.

\section{Experimental}

\subsection{Materials}

PAE was prepared from aromatic dianhydride and aromatic hydroxy diamine by acid chlorination method through esterification of aromatic dianhydride [14]. Photoactive compound was synthesized through the condensation of naphthoquinonediazide sulfonyl chloride and phenolic moieties. HD-8000 was prepared by dissolving the PAE, the NQD compound and the other additives in a solvent, and then filtered through $0.2 \mu \mathrm{m}$ pore-size Teflon filter.

\subsection{Photolithographic evaluation}

Typical process conditions of $\mathrm{HD}-8000$ in the cured thickness range of 2 to $11 \mu \mathrm{m}$ are shown in Table 1 . (For the thickness of 2 to $4 \mu \mathrm{m}$, the lower viscosity version, $\mathrm{HD}-8001$, is used.)

\subsection{Film properties and adhesion}

Sample specimens for the measurement of film properties were prepared on silicon wafers under the conditions shown in Table 1.

Adhesion to substrates as a function of PCT $\left(121^{\circ} \mathrm{C}\right.$, 2atm.) time was examined by the cross-cut method (JIS $\mathrm{K}-5400$ ) for the films cured in the same manner.

Adhesion strength to molding compounds was measured by the stud-pull method after $168 \mathrm{hr}$ of accelerated test $\left(85^{\circ} \mathrm{C}, 80 \% \mathrm{RH}\right)$; the molding compound was formed into a stud of $3.65 \mathrm{~mm}$ in diameter on the cured HD-8000 film.

\subsection{Dry etching tolerance}

Dry etching conditions are shown in Table 2. The eching rate of HD- 8000 was calculated from the reduced film thickness through dry etching.

Table 2 Dry etching conditions

\begin{tabular}{ccc}
\hline Item & Unit & Condition \\
\hline Machine & - & Ulvac CSE-1110 \\
Pressure & $\mathrm{Pa}$ & 10 \\
RF power & $\mathrm{W}$ & 100 \\
Gas & - & $\mathrm{CF}_{4} / \mathrm{O}_{2}{ }^{11}$ \\
Gas flow rate & sccm & 25 \\
\hline
\end{tabular}

*1: Ratio of $\mathrm{CF}_{4}$ to $\mathrm{O}_{2}$ was varied.

Table 1 Typical process conditions

\begin{tabular}{|c|c|c|c|c|c|c|c|c|}
\hline & & \multirow{3}{*}{ Units } & \multicolumn{5}{|c|}{ Target cured thickness ( $\mu \mathrm{m})$} & \multirow{3}{*}{ Reagent } \\
\hline \multirow{2}{*}{\multicolumn{2}{|c|}{ Process }} & & 2 & 4 & 5 & 8 & 11 & \\
\hline & & & \multicolumn{2}{|c|}{$\mathrm{HD}-8001$} & \multicolumn{3}{|c|}{$\mathrm{HD}-8000$} & \\
\hline \multirow{2}{*}{ Coating } & Pre-spin & $\mathrm{rpm} / \mathrm{sec}$ & \multicolumn{5}{|c|}{$1000 / 5$} & HD-8000 \\
\hline & Spin & $\mathrm{rpm} / \mathrm{sec}$ & $4000 / 30$ & $2200 / 30$ & $3400 / 30$ & $1900 / 30$ & $1400 / 30$ & - \\
\hline \multicolumn{2}{|c|}{ Pre-bake } & ${ }^{\circ} \mathrm{C} / \mathrm{sec}$ & $120 / 100$ & $120 / 120$ & $120 / 130$ & $120 / 180$ & $120 / 260$ & - \\
\hline \multicolumn{2}{|c|}{ Pre-baked thickness } & $\mu \mathrm{m}$ & 3.6 & 7.3 & 9.4 & 14.7 & 18.7 & - \\
\hline Exposure & Dose & $\mathrm{mJ} / \mathrm{cm}^{2}$ & 180 & 250 & 250 & 500 & 700 & - \\
\hline \multirow{4}{*}{ Development } & Puddle 1 & sec & 15 & 32 & 35 & 60 & 90 & \multirow{2}{*}{$2.38 \% \mathrm{TMAH}$} \\
\hline & Puddle 2 & $\mathrm{sec}$ & 15 & 32 & 35 & 60 & 90 & \\
\hline & Rinse & $\mathrm{rpm} / \mathrm{sec}$ & \multicolumn{5}{|c|}{$1000 / 10$} & DI water \\
\hline & Spin dry & $\mathrm{rpm} / \mathrm{sec}$ & \multicolumn{5}{|c|}{$3500 / 10$} & - \\
\hline \multicolumn{2}{|c|}{ Developed thickness } & $\mu \mathrm{m}$ & 2.7 & 6.0 & 7.2 & 11.5 & 15.1 & - \\
\hline \multirow{2}{*}{ Post-bake } & Ramp up & ${ }^{\circ} \mathrm{C} / \mathrm{min}$ & \multicolumn{5}{|c|}{$150-350 / 60$} & \multirow{2}{*}{$\mathrm{N}_{2}$ flow } \\
\hline & Hold & ${ }^{0} \mathrm{C} / \mathrm{min}$ & & & $350 / 30$ & & & \\
\hline \multicolumn{2}{|c|}{ Cured thickness } & $\mu \mathrm{m}$ & 2.0 & 4.2 & 5.1 & 8.2 & 10.9 & - \\
\hline
\end{tabular}




\section{Results and Discussion}

3.1. Photolithographic properties

Photolithographic properties were evaluated for 5, 8 and $11 \mu \mathrm{m}$ cured thickness. Sensitivity curves of HD-8000 are shown in Figure 2. The measure of sensitivity, $E_{\mathrm{t}}$ for 5,8 and $11 \mu \mathrm{m}$ cured thickness are 200 , 350 and $580 \mathrm{~mJ} / \mathrm{cm}^{2}$, respectively. In practical use, exposure dose in $20 \sim 40 \%$ excess of $E_{\text {th }}$ will be recommended to have enough process margin.

Cross-sections of HD-8000 after development and after cure are shown in Figure 3. There is no scum observed in space area after development. This is a distinctive feature of $\mathrm{HD}-8000$ in comparison with solvent developable negative tone PDPIs.

Figure 4 shows the mask linearity for each of the three cured thickness. Good linear correlations are exhibited between mask sizes and pattem critical dimensions for 5 ,
8 and $11 \mu \mathrm{m}$ cured thickness to $2 ; 4$ and $4 \mu \mathrm{m}$, respectively.

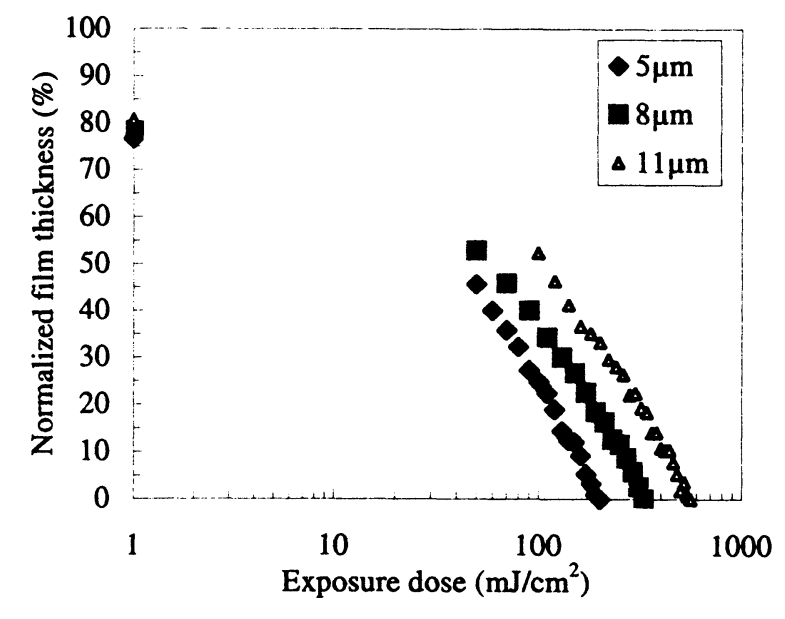

Figure 2 Sensitivity curves of HD-8000 for 5,8 and $11 \mu \mathrm{m}$ cured thickness.
Film thickness: $5 \mu \mathrm{m}$

Pattern size: $3 \mu \mathrm{m}$

Film thickness: $8 \mu \mathrm{m}$ Pattern size: $4 \mu \mathrm{m}$

Film thickness: $11 \mu \mathrm{m}$ Pattern size: $5 \mu \mathrm{m}$
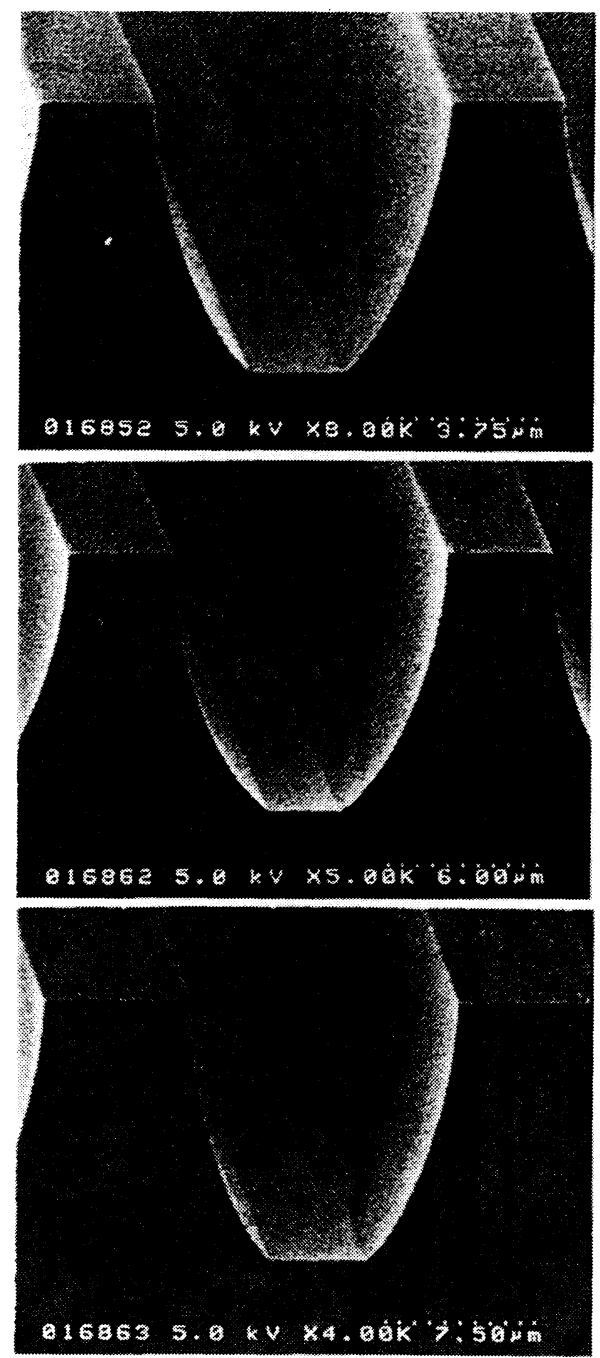

After development
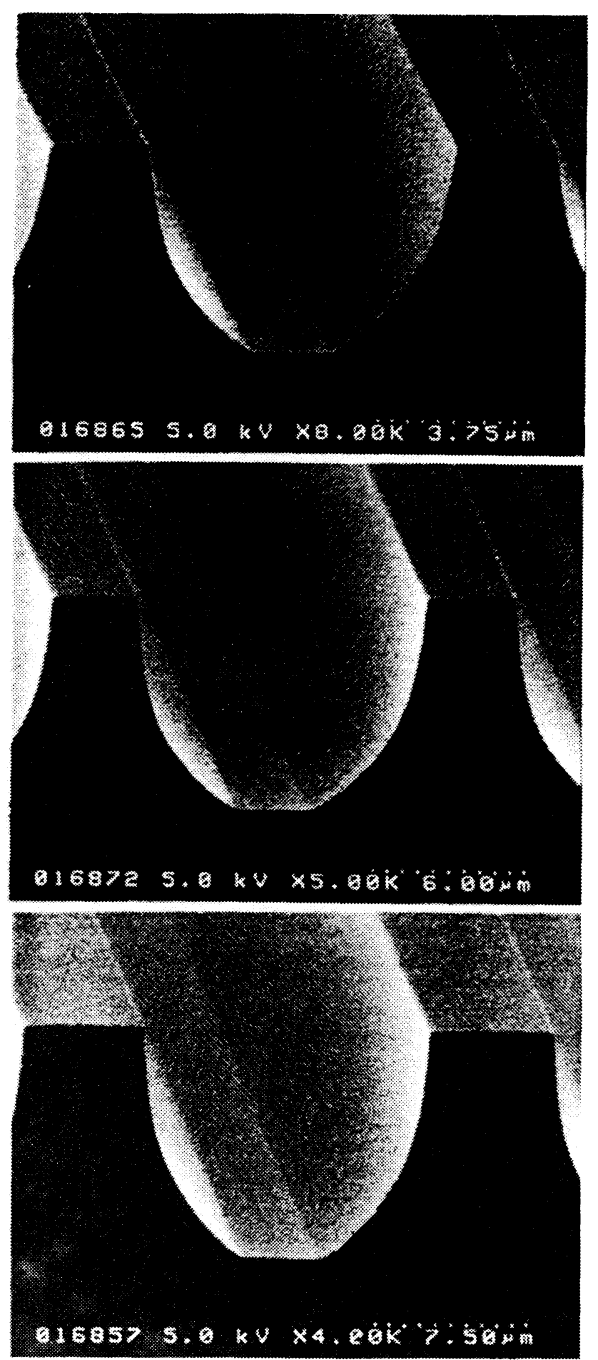

After cure

Figure 3 Cross sections of HD-8000 patterns for 5, 8 and $11 \mu \mathrm{m}$ thickness cured 


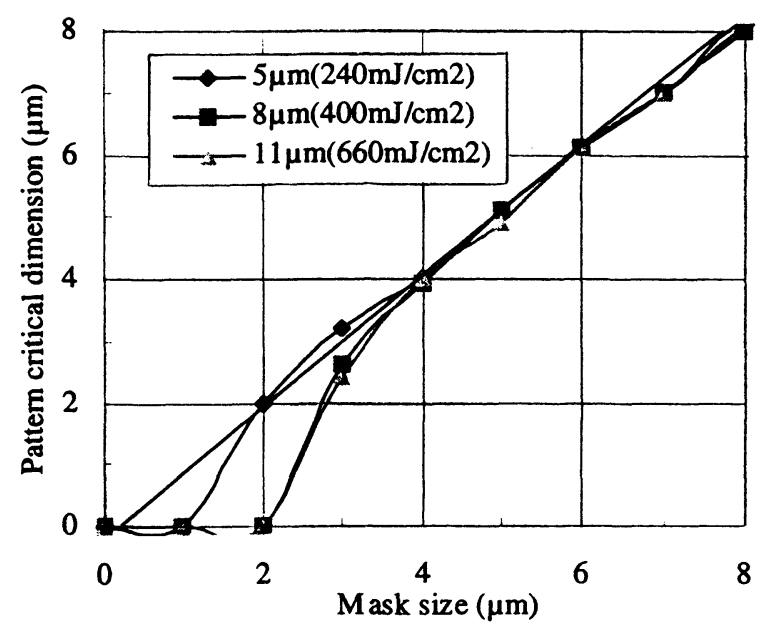

Figure 4 Mask linearity of HD-8000

(1) $+3 \mu \mathrm{m}$

(5) $-1 \mu \mathrm{m}$
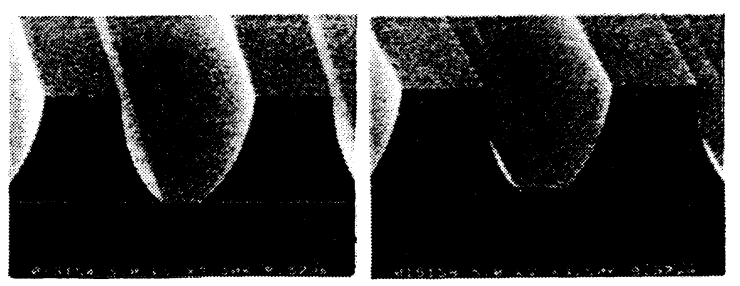

(2) $+2 \mu \mathrm{m}$

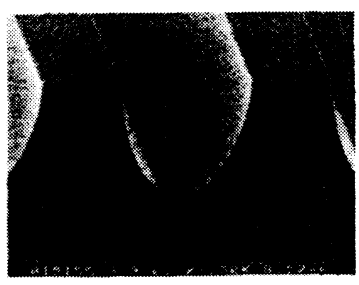

(6) $-2 \mu \mathrm{m}$

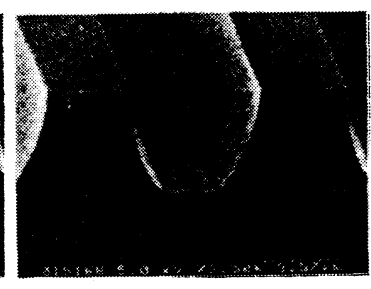

(3) $+1 \mu \mathrm{m}$

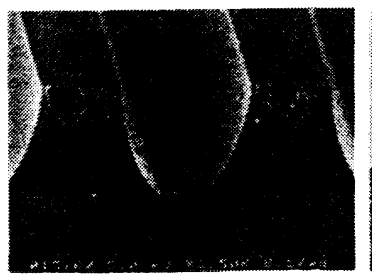

(7) $-3 \mu \mathrm{m}$

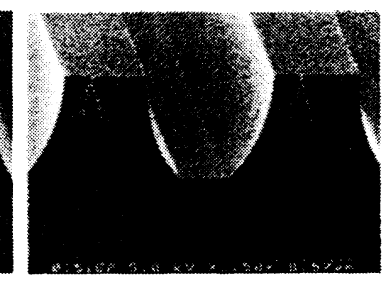

(4) $0 \mu \mathrm{m}$

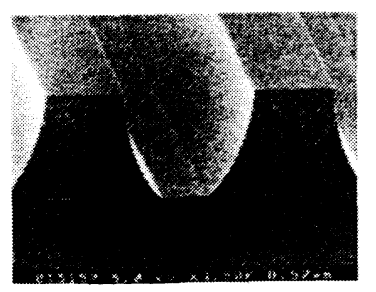

Figure 5 Focus latitude of $\mathrm{HD}-8000$ (Stepper numerical aperture was 0.24 .)

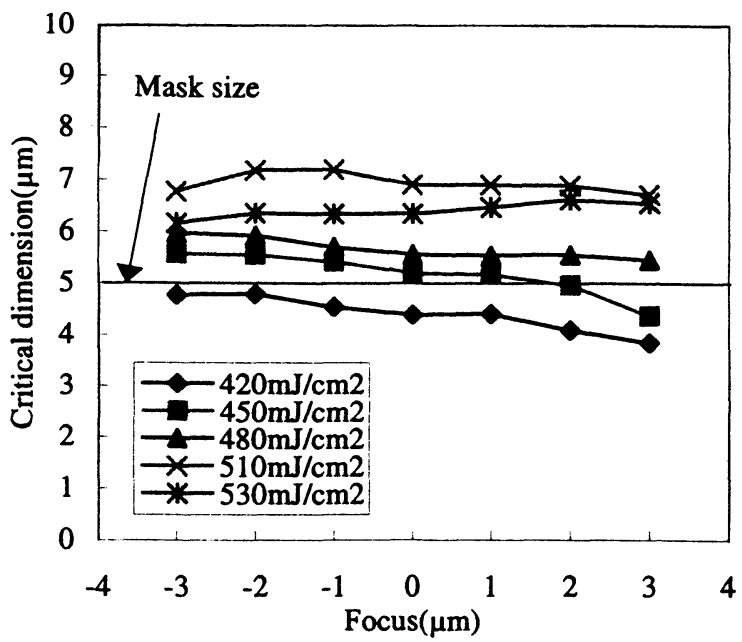

Figure 6 Dependence of critical dimension on focus

PDPIs need to have a wide focus margin, because semiconductor devices just before applying PDPIs have a few microns of trench and stepped topologies. The cross-sections of $\mathrm{HD}-8000$ after development for varied focus values are shown in Figure 5. HD-8000 did not show significant changes in the patterm profile in -3 to +3 $\mu \mathrm{m}$ focus range. Figure 6 shows the dependence of critical dimension on focus for variations of exposure dose. Critical dimension at each exposure dose showed less dependence on focus of -3 to $+3 \mu \mathrm{m}$.

Figure 7 shows the stability of $E_{\text {th }}$ and film retention after development for process holding time. Both $E_{\mathrm{th}}$ and film retention are stable for over 70 hours of time between pre-bake and exposure. The stability for the hold time between exposure and development is also kept for over 70 hours.

\subsection{Film properties}

Film properties of $\mathrm{HD}-8000$ are summarized in Table 3 with referring to those of PIX-3400, which is a typical non-photodefinable polyimide and has been widely employed in semiconductor manufacture. HD-8000 demonstrated film properties almost equivalent to PIX-3400.

The adhesion of HD-8000 was evaluated for six kinds of substrate: $\mathrm{Si}, \mathrm{SiO}, \mathrm{SiN}, \mathrm{Al}$, Ti and $\mathrm{SiNO}$. The results of the cross-cut method before and after PCT are shown in Table 4. No delamination was observed even after 1000 hours of PCT on all kinds of substrates tested.

Table 5 shows the adhesion strength to molding compounds. HD-8000 demonstrated stronger adhesion than PIX-3400 to any of following three kinds of molding compounds: cresol-novolac, biphenyl and dicyclo types. 
(1) Pre-bake - exposure

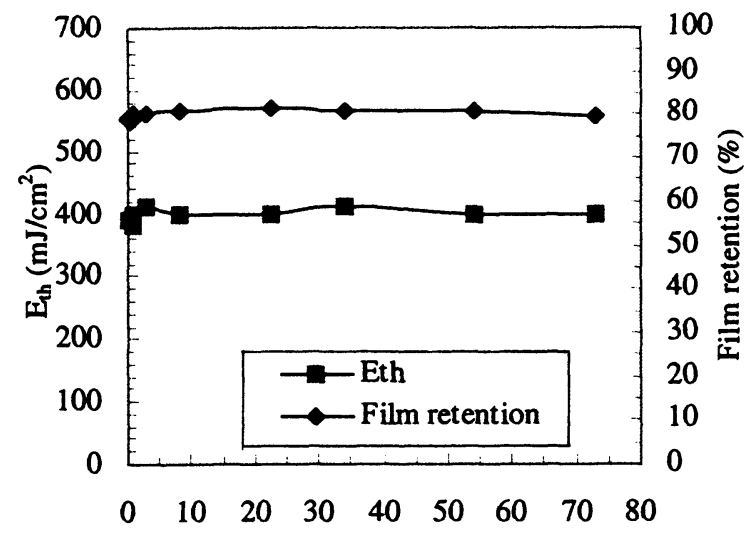

Hold time between pre-bake and exposure (hr)

(2) Exposure - development

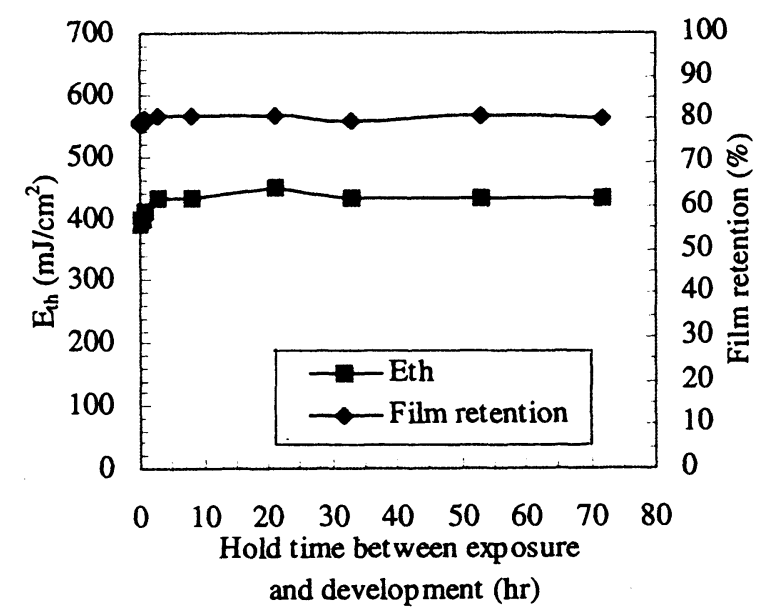

Figure 7 Stability of $E_{\mathrm{h}}$ and film retention for process hold time

Table 3 Film properties of HD-8000

\begin{tabular}{ccccc}
\hline tiem & $\begin{array}{c}\text { Measurement } \\
\text { method }\end{array}$ & Unit & HD-8000 & PIX-3400*1 \\
\hline $\mathrm{Tg}$ & $\mathrm{TMA}$ & ${ }^{\circ} \mathrm{C}$ & 300 & 295 \\
$\mathrm{CTE}$ & & $\mathrm{ppm} / \mathrm{C}$ & 47 & 55 \\
\hline $\begin{array}{c}\text { Tensile strength } \\
\text { Elastic } \\
\text { modulus }\end{array}$ & Autograph & $\mathrm{MPa}$ & 122 & 114 \\
Elongation & & $\mathrm{GPa}$ & 2.5 & 2.1 \\
\hline $\begin{array}{c}1 \% \text { Weight } \\
\text { loss temp. }\end{array}$ & $\mathrm{TGA}$ & ${ }^{\circ} \mathrm{C}$ & 403 & 450 \\
$5 \%$ & & ${ }^{\circ} \mathrm{C}$ & 433 & 531 \\
\hline
\end{tabular}

*1: Typical non-photodefinable polyimide
Table 4 Adhesion to substrates

\begin{tabular}{ccccccc}
\hline PCT time & Si & SiO & SiN & Al & Ti & SiNO \\
\hline $0 \mathrm{hr}$ & $100 / 100$ & $100 / 100$ & $100 / 100$ & $100 / 100$ & $100 / 100$ & $100 / 100$ \\
$100 \mathrm{hr}$ & $100 / 100$ & $100 / 100$ & $100 / 100$ & $100 / 100$ & $100 / 100$ & $100 / 100$ \\
$300 \mathrm{hr}$ & $100 / 100$ & $100 / 100$ & $100 / 100$ & $100 / 100$ & $100 / 100$ & $100 / 100$ \\
$500 \mathrm{hr}$ & $100 / 100$ & $100 / 100$ & $100 / 100$ & $100 / 100$ & $100 / 100$ & $100 / 100$ \\
$1000 \mathrm{hr}$ & $100 / 100$ & $100 / 100$ & $100 / 100$ & $100 / 100$ & $100 / 100$ & $100 / 100$ \\
\hline *X/100 means that X square pieces among 100 pieces did not \\
peel off after the cross-cut test.
\end{tabular}

Table 5 Adhesion to molding compounds

\begin{tabular}{cccc}
\hline Molding compound & Unit & HD-8000 & PIX-3400 \\
\hline Cresol-novolactype & $\mathrm{kgf} / 10.2 \mathrm{~mm}^{2}$ & 6.4 & 4.5 \\
Biphenyl type & $\mathrm{kgf} / 10.2 \mathrm{~mm}^{2}$ & 4.6 & 3.2 \\
Dicyclotype & $\mathrm{kgf} / 10.2 \mathrm{~mm}^{2}$ & 3.8 & 2.0 \\
\hline
\end{tabular}

(1) Dry etch rates of $\mathrm{HD}-8000$ and $\mathrm{SiN}$

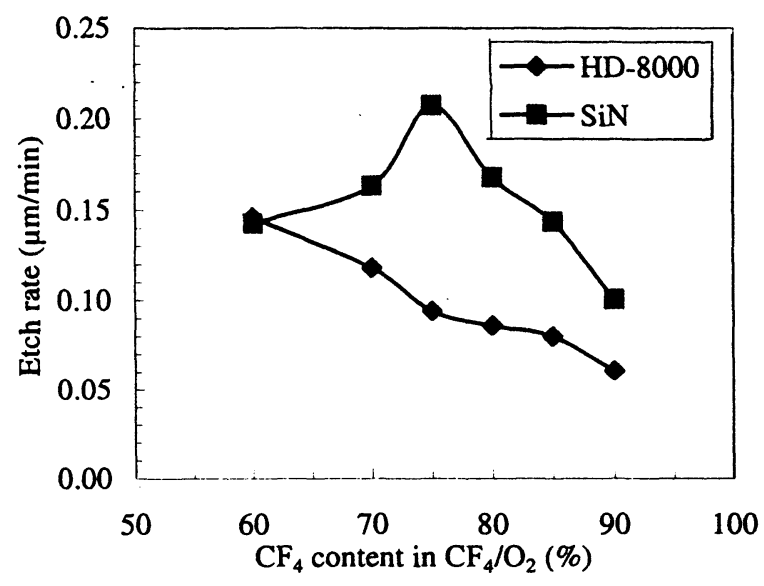

(2) Selectivity of $\mathrm{HD}-8000$

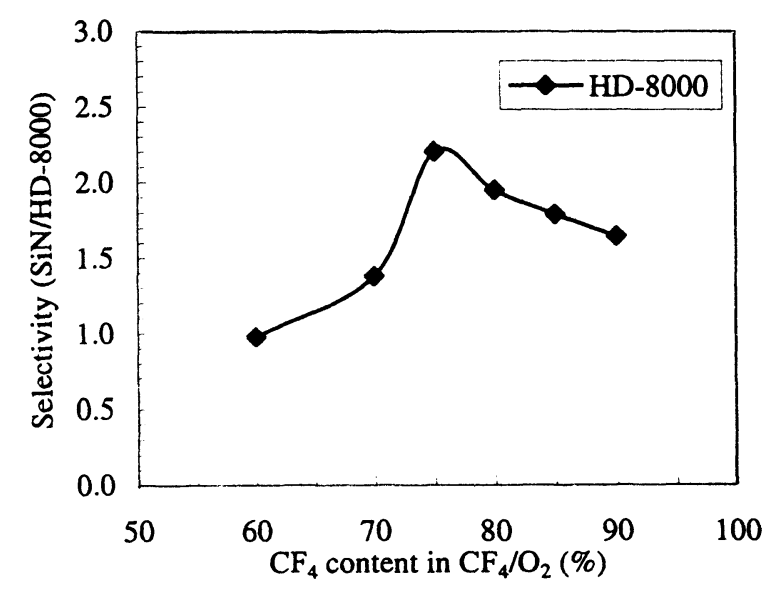

Figure 8 Dry etch tolerance of $\mathrm{HD}-8000$ 
(a) Before dry etching

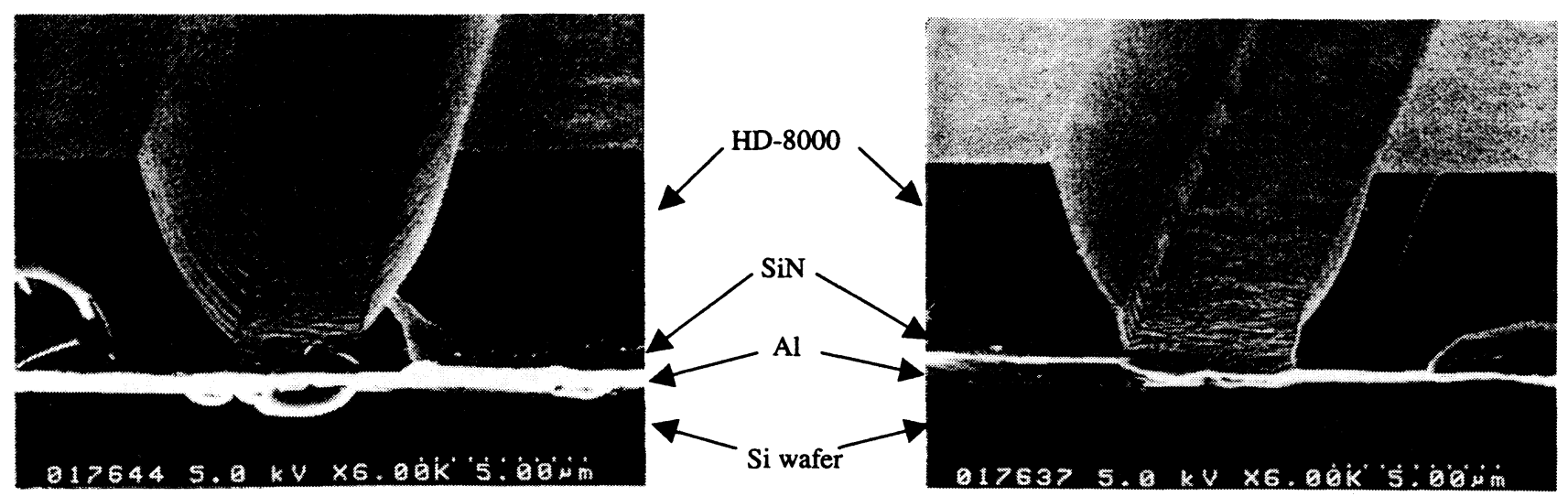

Figure 9 Dry etching of SiN layer with HD-8000 mask

*Spacewidth of HD-8000 pattern is 5 um.

On the Basis of the results shown in Table 3 to 5 , $\mathrm{HD}-8000$ is expected to exhibit the reliability equivalent to PIX-3400.

\subsection{Dry etching tolerance}

Owing to high resolution under $5 \mu \mathrm{m}, \mathrm{HD}-8000$ can be used as a dry etching mask for passivation layers. This allows the elimination of photoresist process for the dry etching. Figure 8 shows the dry etching tolerance of cured $\mathrm{HD}-8000$ and silicon nitride (SiN). The etching selectivity, which is defined as the ratio of etching rates of $\mathrm{SiN}$ to $\mathrm{HD}-8000$, shows a maximum at $75 / 25$ of $\mathrm{CF}_{4} / \mathrm{O}_{2}$ gas composition. As shown in Figure 9, the dry etching of SiN layer at this gas composition was demonstrated with the mask of cured HD-8000. The SiN layer of $5 \mu \mathrm{m}$ width space was clearly etched, while HD- 8000 pattern seemed almost the same.

\section{Conclusion}

We have developed a new aqueous positive tone photodefinable polyimide, HD-8000, for semiconductor stress buffer coats, inter layer dielectrics and the like. HD-8000 has good photolithographic properties: high resolution, wide focus margin and high stability for process holding time. HD-8000 exhibits film properties almost equivalent to non-photodefinable polyimide and also excellent adhesion to substrates and molding compounds. Cured patterns of HD-8000 can be used as a dry etching mask for the passivation layer of SiN.

\section{References}

1. K.Sato, S.Harada, A.Saiki, T.Kimura, T.Okubo, K.Murai, IEEE Trans.Parts. Hybrid and Packaging, PHP-9 (1973) 176

2. M.G.Moss, R.M.Cuzmar, T.Brewer, Proc.SPIE-Int.Soc.Opt.Eng., 1086 (1989) 396

3. O.Haba, M.Okazaki, T.Nakayama, M.Ueda, J.Photopolym. Sci.Technol., 10 (1997) 55

4. N.Kihara, M.Oba, T.Mikosiba, R.Horiguti, Jpn. Kokai 3-115461 (1991)

5. R.H.Hayase, N.Kihara, N.Oyasato, S.Matake, M.Oba, Proc.SPIE, 1466 (1991) 438

6. D.N.Khanna, W.H.Mueller, Polym.Eng., 29 (1989) 954

7. T.Omote, H.Mochizuki, K.Koseki, T.Yamaoka, Makromol.Chem., Rapid Commun., 10 (1989) 521

8. T.Abe, M.Mishina, N.Kohtoh, J.Photopolym. Sci.Technol., 5 (1992) 327

9. S.Kubota, T.Moriwaki, T.Ando, A.Fukami, J.Macromol.Sci.-Cem., A24(12) (1987) 1407

10. T.Omote, K.Koseki, T.Yamaoka, J.Polym.Sci.: Part C: Polym. Letters, 28 (1990) 59

11. B.Ho, J.Chen, W.Perng, C.Lin, L.Chen, J.Appl.Polym.Sci., 67 (1998) 1313

12. S.Akimoto, D.Kato, M.Jikei, M.Kakimoto, J.Photopolym. Sci.Technol., 12 (1999) 245

13. To be publishes elsewhere.

14. M.Ohe, S.Uchimura, Jpn. Kokail1-315140 (1999) 